\title{
2'-Hydroxyflavanone: A novel strategy for targeting breast cancer
}

\author{
Jyotsana Singhal ${ }^{1, *}$, Lokesh Nagaprashantha ${ }^{1,{ }^{*}}$, Shireen Chikara ${ }^{1}$, Sanjay Awasthi ${ }^{2}$, \\ David Horne ${ }^{1}$ and Sharad S. Singhal ${ }^{1}$ \\ ${ }^{1}$ Department of Molecular Medicine, Beckman Research Institute of City of Hope, Comprehensive Cancer Center and National \\ Medical Center, Duarte, CA 91010, USA \\ ${ }^{2}$ Department of Medical Oncology, Texas Tech University Health Sciences Center, Lubbock, TX 79430, USA \\ *Authors contributed equally to this work \\ Correspondence to: Sharad S. Singhal, email: ssinghal@coh.org \\ Keywords: breast cancer, 2'-hydroxyflavanone, RLIP76, VEGF, xenografts \\ Received: June 22, $2017 \quad$ Accepted: July 12, $2017 \quad$ Published: August 24, 2017 \\ Copyright: Singhal et al. This is an open-access article distributed under the terms of the Creative Commons Attribution License \\ 3.0 (CC BY 3.0), which permits unrestricted use, distribution, and reproduction in any medium, provided the original author and \\ source are credited.
}

\section{ABSTRACT}

Breast cancer is the most common cancer in women that is driven by crosstalk with hormonal and cellular signaling pathways. The natural phytochemicals, due to broad-spectrum anti-inflammatory and anti-cancerous properties, present with novel opportunities for targeting breast cancer. Intake of citrus fruits is known to reduce the risk for incidence of breast cancer. Hence, we tested the efficacy of citrus flavonoid 2'-hydroxyflavanone (2HF) in breast cancer. $2 \mathrm{HF}$ inhibited survival, clonogenic ability, cell cycle progression and induced apoptosis in breast cancer cells. 2HF also decreased VEGF levels and inhibited migratory capacity of breast cancer cells. Administration of $2 \mathrm{HF}$ led to regression of triple-negative MDA-MB-231 tumors in the mice xenograft model. 2HF decreased the levels of RLIP76 both in vitro studies and in vivo MDA-MB-231 xenograft model of breast cancer. Western blot and histopathological analyses of resected tumors showed a decline in the levels of survival and proliferation markers Ki67, pAkt, survivin, and cell cycle proteins CDK4 and cyclin B1. 2HF treatment led to inhibition of angiogenesis as determined by decreased VEGF levels in vitro and angiogenesis marker CD31 in vivo. 2HF reversed the pro-/anti-apoptotic ratio of BAX/BCL-2 by decreasing anti-apoptotic protein BCL2 and increasing pro-apoptotic proteins BAX and BIM in vivo. 2HF also decreased the mesenchymal markers vimentin and fibronectin along with causing a parallel increase in pro-differentiation protein E-cadherin. Collectively, the ability of $2 \mathrm{HF}$ to decrease RLIP76, VEGF and regulate critical proliferative, apoptotic and differentiation proteins together provides strong rationale to further develop $2 \mathrm{HF}$ based interventions for targeting breast cancer.

\section{INTRODUCTION}

Breast cancer remains a leading cause of cancerrelated deaths among women worldwide despite significant advances in targeted therapies and screening techniques for early detection [1-4]. Breast cancer is a very aggressive tumor with notoriously poor prognosis following metastases [5]. The known risk factors for the onset of breast cancer include family history, Li-
Fraumeni syndrome, atypical hyperplasia of the breast, late-age at first full-term pregnancy, early menarche, and late menopause [6-8]. Selective estrogen-receptor (ER) modulators (e.g., tamoxifen) appear promising for prevention of breast cancer; however, they are largely ineffective against ER-negative breast cancers [9, 10]. Moreover, selective ER modulators have serious side effects such as increased risk of uterine cancer, thromboembolism, cataracts, and perimenopausal 
symptoms [10, 11]. Triple negative breast cancer (TNBC), characterized by the absence of ER, progesterone receptor (PR) and lacking in HER2 gene expression, is associated with more aggressive phenotype [12]. TNBC is more prevalent in younger females and accounts for about 10$20 \%$ of breast cancers with characteristic poor prognosis and low survival rates [5]. In addition, about 25-46\% patients with TNBC are at higher risk of brain metastasis [13]. Therefore, novel strategies for targeting breast cancers, irrespective of hormone receptor and HER2 status, are highly desirable.

RLIP76 (a $76 \mathrm{kDa}$ ral-binding protein, RALBP1 or RLIP76) is a multi-functional rac and ral effector that also functions as a major and multi-specific glutathioneconjugate (GS-E) transporter of mercapturic acid pathway (MAP) [14]. The knockout of RLIP76 leads to inhibition of epithelial carcinogenesis [15]. RLIP76 is up-regulated in multiple cancers and is known to induce apoptotic- and drug-resistance by mediating active efflux of the GS-Es of chemotherapy drugs and toxic products of lipid peroxidation [14-22]. RLIP76 also regulates the endocytosis of receptorligand complexes in IGF and EGFR signaling [15]. RLIP76 has been shown to be an essential factor in determining the proliferative potential and metastatic signaling of cancers [16-22]. Due to its multiple regulatory effects on the incidence, proliferation, invasion and metastases of cancers, RLIP76 represents a vital target for breast cancer.

Natural phytochemicals have received increasing attention in recent years for the discovery of anticancer agents [23]. Flavonoids, a large group of polyphenolic compounds present in foods and beverages of plant origin, have anti-oxidant, anti-inflammatory, anti-mutagenic, and anti-proliferative properties [24-26]. The intake of citrus fruits and citrus juice has been associated with protection from breast cancer incidence in both animal models and in humans [27, 28]. Hence, we tested the effect of citrus flavonoid 2'-Hydroxyflavanone (2HF) in vitro and in vivo on the survival and progression of breast cancer. MCF-7 breast cancer cells are known to be $\mathrm{ER}^{+}, \mathrm{PR}^{+}$and HER2- while MDA-MB-231 cells are known to have characteristics of ER', $\mathrm{PR}^{-}$and HER2- (triple-negative) breast cancers [29]. In the present study, we observed that $2 \mathrm{HF}$ treatment inhibits the growth of breast cancer cells in vitro, reduces the levels of RLIP76 and VEGF, and inhibits the progression of triple-negative MDA-MB-231 breast tumors in xenograft mouse model of breast cancer. The results from our collective in vitro and in vivo investigations elucidated the anticancer potential of $2 \mathrm{HF}$ as a novel small molecule candidate drug for targeting breast cancer.

\section{RESULTS}

\section{HF inhibits proliferation and colony forming ability in breast cancer cells in vitro}

$2 \mathrm{HF}$ is a novel phytochemical that is known for anti-inflammatory and anticancer properties [24-26].
The structure of $2 \mathrm{HF}$ is represented in Figure 1A. We conducted in vitro studies to assess the impact of $2 \mathrm{HF}$ on cell survival, clonogenic ability and cytotoxicity. MTT assay conducted following $48 \mathrm{~h}$ of $2 \mathrm{HF}$ treatment revealed that $2 \mathrm{HF}$ is effective in inhibiting survival of MCF-7 as well as aggressive MDA-MB-231 and T47D breast cancer cell lines with an $\mathrm{IC}_{50}$ ranging from $24+2$ to $30+3 \mu \mathrm{M}$ (Figure 1B, Table 1A) [30]. The CellTiter-Glo luminescent assay also confirmed inhibitory effects of $2 \mathrm{HF}$ in breast cancer cells with an $\mathrm{IC}_{50}$ ranging from $27 \pm 2$ to $30 \pm 3 \mu \mathrm{M}$ (Figure 1B, Table 1A) [31]. The $50 \mu \mathrm{M}$ of $2 \mathrm{HF}$ treatment caused $\sim 45-75 \%$ inhibition of colony forming ability of MCF-7, T47D, and MDA-MB-231 breast cancer cell lines (Figure 1C, Table 1B). In addition, crystal violet staining revealed decrease in viable cells following $2 \mathrm{HF}$ treatment (Figure 1D). Interestingly, MCF10A normal human mammary epithelial cells were significantly more resistant to 2HF-mediated anti-proliferative effects as compared with MCF-7, MDA-MB-231 and T47D breast cancer cells (Figure 1).

\section{HF induces apoptosis, inhibits migratory capacity, decreases RLIP76 and VEGF, and induces cell cycle arrest in breast cancer cells in vitro}

2HF-induced apoptotic effects were initially assessed by Annexin V assay which showed a concentration dependent induction of apoptosis in both MCF-7 and MDA-MB-231 breast cancer cells (Figure 2). A $50 \mu \mathrm{M}$ treatment of $2 \mathrm{HF}$ for $24 \mathrm{~h}$ induced apoptosis in MCF-7, MDA-MB-231 and T47D breast cancer cells, while sparing normal MCF10A cells as determined by DNA fragmentation in TUNEL apoptosis assay (Figure $3 \mathrm{~A})$. The levels of VEGF and the ability of cancer cells to migrate determine their ability to form blood vessels and metastasize [32]. 2HF treatment lead to $\sim 40-60 \%$ inhibition of VEGF levels with a marked anti-VEGF effect in aggressive MDA-MB-231 cells as compared to MCF7 and T47D cells (Figure 3B). Wound healing assay at $6 \mathrm{~h}, 12 \mathrm{~h}$, and $24 \mathrm{~h}$ showed that $2 \mathrm{HF}$ treatment inhibits the migratory capacity of MCF-7 and MDA-MB-231 breast cancer cells (Figure 3C).

RLIP76 is a critical protein essential for migration, survival, and proliferation of cancer cells [14-22]. We further assessed the endogenous levels of RLIP76 in breast cancer cells and the effect of $2 \mathrm{HF}$ on the levels of RLIP76 protein expression in breast cancer cells. Western blot analyses revealed an elevated level of RLIP76 in MCF-7, MDA-MB-231 and T47D cells (Figure 4A). The treatment of MCF-7, MDA-MB-231 and T47D cells with $25 \mu \mathrm{M}$ of $2 \mathrm{HF}$ for $24 \mathrm{~h}$ led to $\sim 50-$ $60 \%$ decrease in the levels of RLIP76 protein in all the treated cell lines (Figure 4B). This finding denotes that inhibition of RLIP76 protein expression is a common mechanism, along with inhibition of VEGF, by which the anticancer effects of $2 \mathrm{HF}$ are mediated in breast 
Table 1A: $\mathrm{IC}_{50}(\mu \mathrm{M})$ values in breast cancer cells following $2 \mathrm{HF}$ treatment

\begin{tabular}{lcc}
\hline Cell Line & MTT Assay & CellTiter-Glo Assay \\
\hline MCF10a & ND & ND \\
MCF-7 & $24 \pm 2$ & $27 \pm 2$ \\
T47D & $26 \pm 2$ & $28 \pm 3$ \\
MDA-MB-231 & $30 \pm 3$ & $30 \pm 3$ \\
\hline
\end{tabular}

NOTE: Drug sensitivity assays were performed following $2 \mathrm{HF}$ treatment for $48 \mathrm{~h}$ in both MTT and CellTiter-Glo assays.

ND: Not detected. Values represent mean $\pm \mathrm{SD}$ from three separate determinations with eight replicates $(n=24)$.

Table 1B: Colony formation assay following $2 \mathrm{HF}$ treatment in breast cancer cells

\begin{tabular}{lcc}
\hline Cell Line & $\begin{array}{c}\text { \% Colony formation } \\
\text { (as compared to Controls) }\end{array}$ & SD \\
\hline MCF10a & 94 & 5 \\
MCF-7 & 37 & 4 \\
T47D & 44 & 9 \\
MDA-MB-231 & 28 & 7 \\
\hline
\end{tabular}

NOTE: Values represent mean \pm SD from three separate determinations with triplicates $(n=9)$.

A

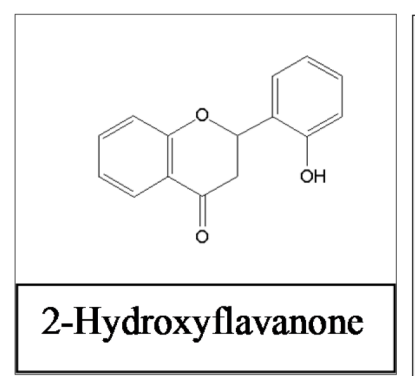

B

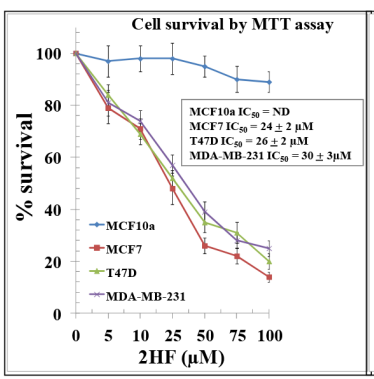

C
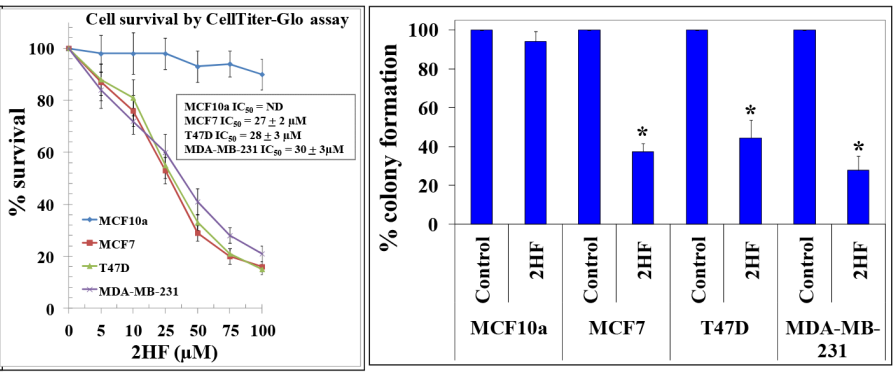

D

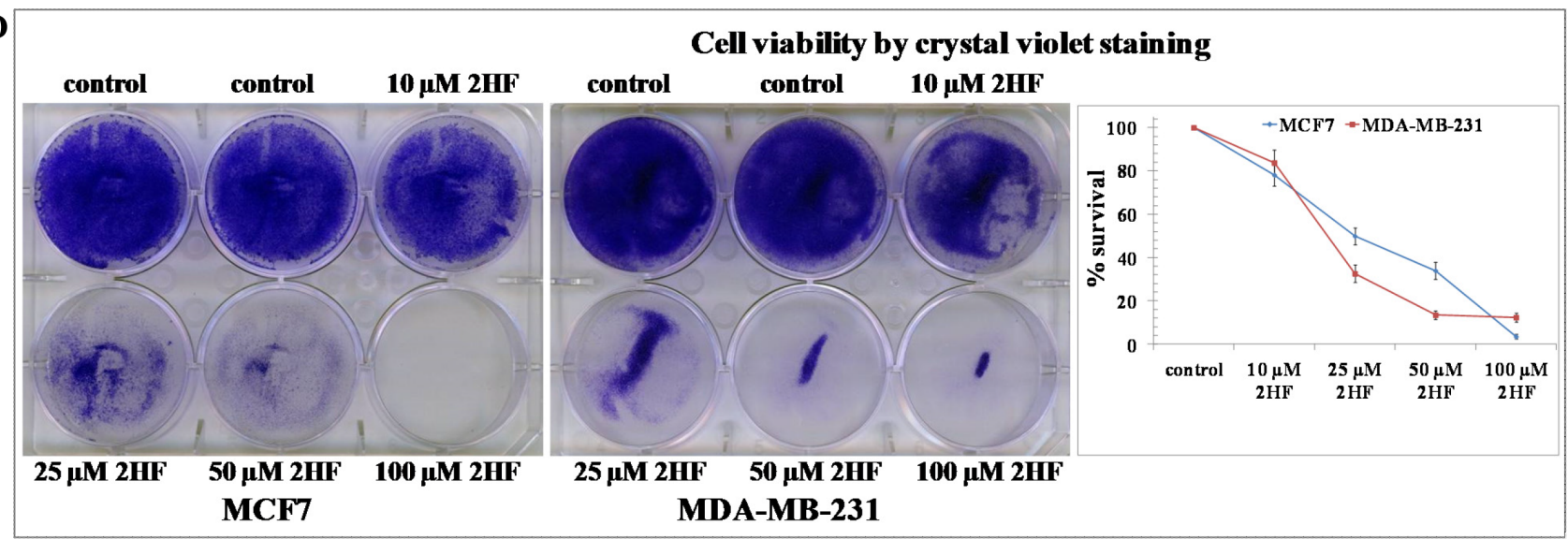

Figure 1: 2HF inhibits breast cancer cell survival sparing normal breast epithelial cells. The chemical structure of $2 \mathrm{HF}$ (panel A). Drug-sensitivity assays were performed by MTT as well as CellTiter Glo assay using $2 \mathrm{HF}$ at $48 \mathrm{~h}$ post treatment to determine $\mathrm{IC}_{50}$. Values are presented as mean \pm SD from three separate determinations with 8 replicates each $(\mathrm{n}=24)$ (panel B). Colony-forming assay was performed and the colonies were counted using Innotech Alpha Imager HP. The bars represent the $\%$ colony formation $\left({ }^{*} p<0.001\right.$ compared with Control) (panel C). Cells were treated with various concentrations of $2 \mathrm{HF}$. After a $48 \mathrm{~h}$ exposure, cell viability was assessed by crystal violet staining. Values are presented as mean \pm SD from three separate experiments as compared with the Control $(n=3)(\mathbf{p a n e l} \mathbf{D})$. 


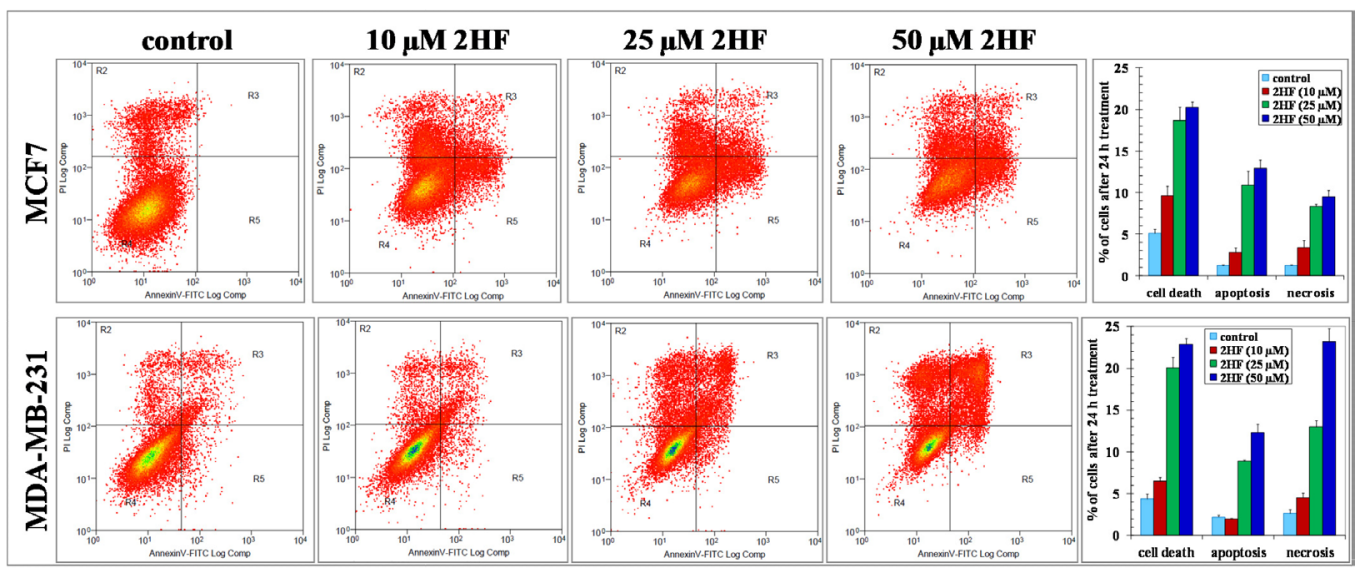

Figure 2: 2HF induces apoptosis as assessed by Annexin V Assay. MCF7 and MDA-MB-231 cells were incubated with or without test compound for $24 \mathrm{~h}$, washed and harvested. The cells were then fixed and double stained with Annexin V-FITC and PI, and analyzed by flow cytometry. The percentage distribution of normal/viable, early apoptotic, late apoptotic, and necrotic cells was calculated using Summit software. The experiment was repeated three times and similar results were obtained. $* \mathrm{p}<0.001$, compared with Control.

$\mathbf{A}$

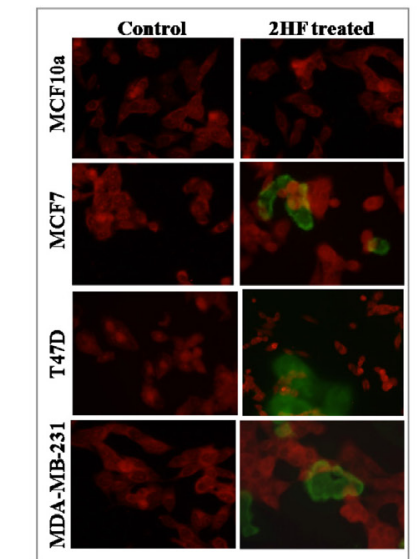

C

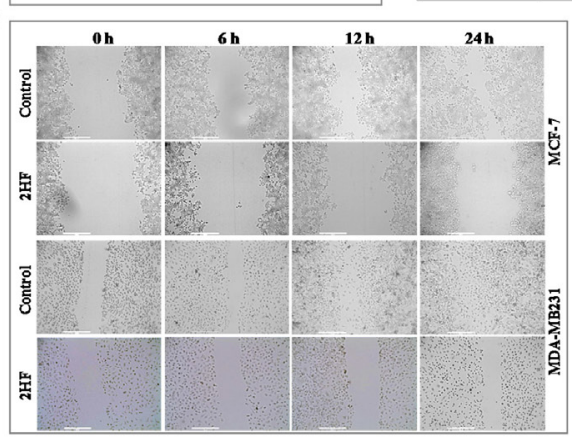

B
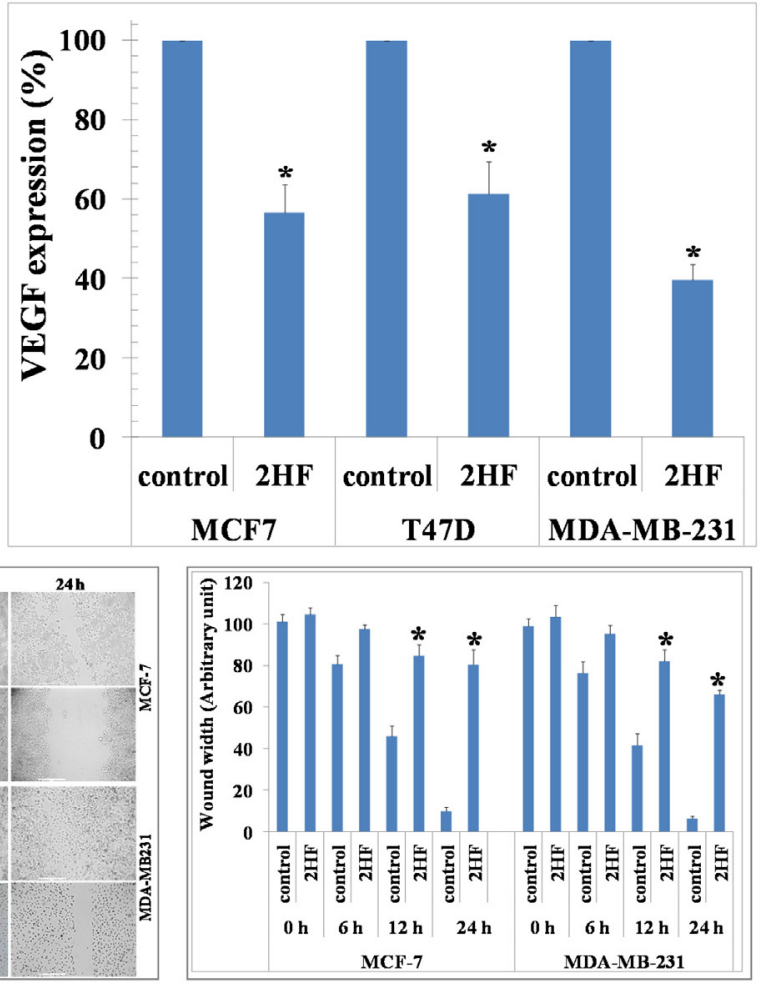

Figure 3: 2HF induces apoptosis as assessed by TUNEL assay, decreases VEGF and inhibits migration of breast cancer cells. Normal (MCF10a) and breast cancer (MCF-7, T47D, MDA-MB-231) cells were grown on cover-slips. For 2HF treatment, cells were incubated with $50 \mu \mathrm{M} 2 \mathrm{HF}$ for $24 \mathrm{~h}$ before TUNEL assay using Promega fluorescence detection kit according to the protocol provided by the manufacturer. Slides were analyzed by laser scanning fluorescence microscope (Zeiss LSM 510 META). Photographs taken at identical exposure at $400 \mathrm{x}$ magnification are presented. Apoptotic cells showed green fluorescence (panel A). VEGF expression in Control and 2HF-treated cells by enzyme-linked immunosorbent assay kit (R\&D System): ${ }^{*} p<0.01$ compared with Control (panel B). $2 \mathrm{HF}$ treatment inhibited migration of cultured MCF-7 and MDA-MB-231cells:MCF-7 and MDA-MB-231 cells were grown in 6-well plates to form monolayer. Wounds were created using $0.1 \mathrm{ml}$ sterile tip. Cell migration capacity was measured by the time taken to heal the wound in Control and 2HF-treated cells. Representative images depicting the effect of 2HF treatment on MCF-7 and MDA-MB-231 cells migration. Significantly different $\left({ }^{*} p<0.001\right)$ compared with Control by Student's $t$ test (panel C). 
cancer cells with diverse ER, PR and HER2 status (Figure 3B and 4B). The anti-proliferative effects of $2 \mathrm{HF}$ were further examined by cell cycle FACS analysis. $2 \mathrm{HF}$ treatment caused G2/M phase arrest in MCF-7 and MDA-MB-231 human breast cancer cells with $\sim 40 \%$ cells accumulated in G2 phase (Figure 4C). Following the assessment of in vitro anticancer properties of $2 \mathrm{HF}$ in MCF-7, MDA-MB-231 and T47D breast cancer cells, we further investigated the efficacy of $2 \mathrm{HF}$ in mice xenograft model established using aggressive MDAMB-231 breast cancer cells.

\section{HF administration inhibits the growth of MDA- MB-231 xenografts in nude mice}

For breast cancer xenograft studies, a $0.1 \mathrm{~mL}$ suspension containing $1 \times 10^{6}$ MDA-MB-231 cells was injected subcutaneously on right flank of female nude mice above the hind limb. Treatment was started 10 days after MDA-MB-231 cells were implanted, a time point when palpable tumor growth was seen in our mice xenograft model. Photographs of animals were taken at day 1 , day 10 , day 20 , day 40 , and day 60 after subcutaneous injection, and are shown for all groups (Figure 5). Tumors grew more slowly in mice xenografts administered with $2 \mathrm{HF}$ than in respective untreated control mice. During the course of study, the average tumor size in mice treated with 25,50 , and $100 \mathrm{mg} / \mathrm{kg}$ b.w. $2 \mathrm{HF}$ was significantly lower when compared with vehicle-treated controls. Our in-vivo studies showed that oral administration of $2 \mathrm{HF}$ to nude mice bearing aggressive MDA-MB-231 breast cancer xenografts leads to significant inhibition of tumor progression in $2 \mathrm{HF}$ treated groups with uncontrolled tumor growth observed in the animals treated with vehicle
A

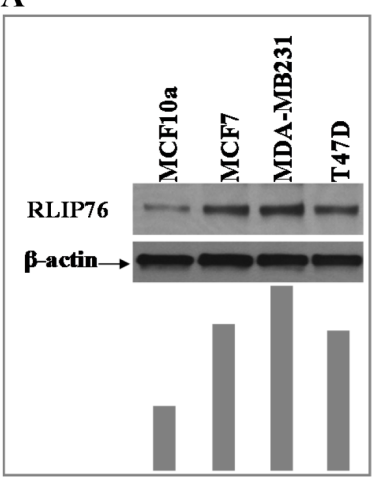

B

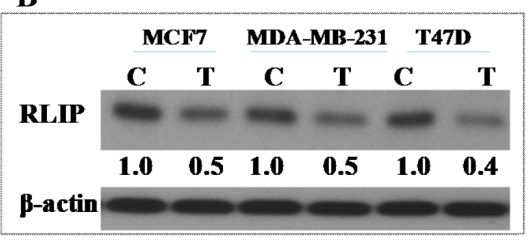

C

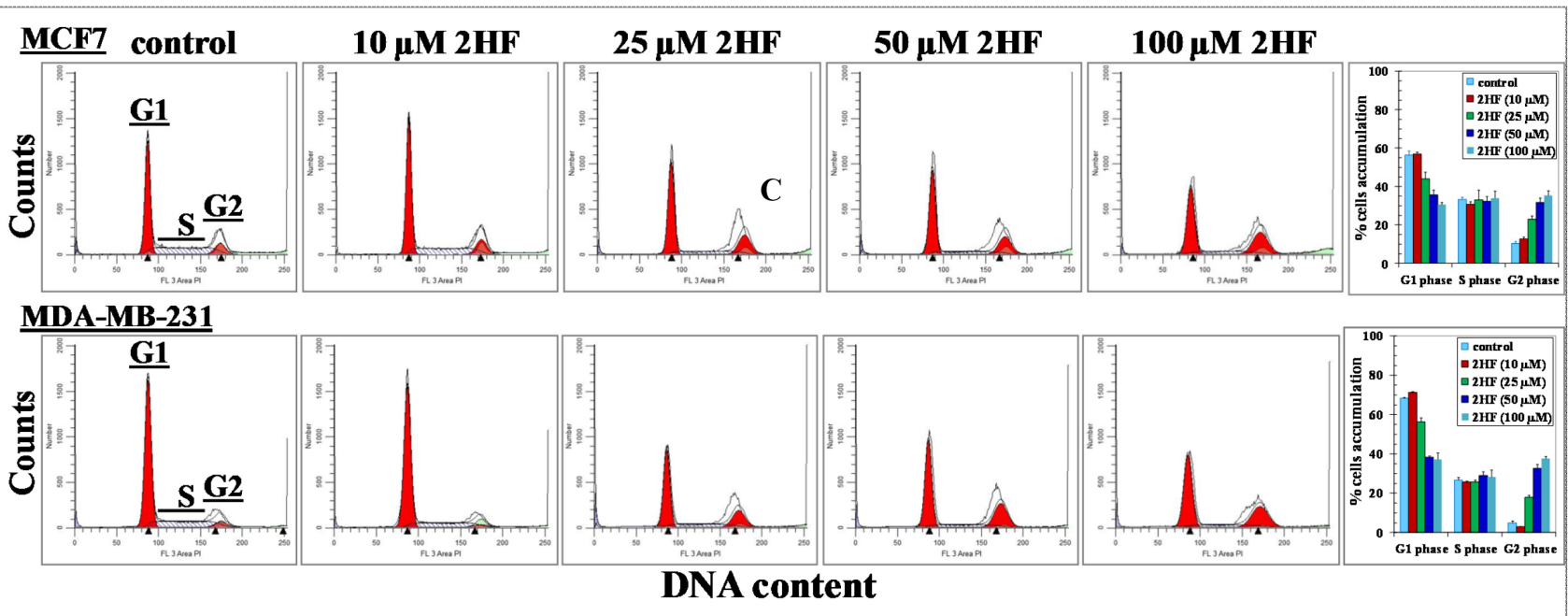

Figure 4: 2HF decreases RLIP76 protein levels and inhibits cell cycle progression in human breast cancer cells. Aliquots of crude membrane extracts of respective cells were analyzed by Western blot analyses against anti-RLIP76 IgG. Results were quantified by scanning densitometry. $\beta$-actin was used as an internal control (panel A). Western blots show the change in cellular RLIP76 protein content upon treatment of the human breast cancer cell lines with $25 \mu \mathrm{M} 2 \mathrm{HF}$ for $24 \mathrm{~h}$. $\beta$-actin was used as a loading control. Numbers below the blots represent the fold change in the level of RLIP76 as compared to Control as determined by densitometry (panel B). Inhibitory effect of $2 \mathrm{HF}$ on cell cycle distribution was determined by fluorescence activated cell sorting (FACS) analysis. Experimental details are given in the Methods section. The stained cells were analyzed using a CyAn ADP cytometer (Beckman Coulter Inc) (panel C). The experiment was repeated three times and similar results were obtained, ${ }^{*} p<0.001$, compared with Control. 
only ( $p<0.002$; Figure 6A). At day 60 following tumor cell injection, the average tumor size in control mice was about 3.3- to 5.6-fold higher as compared to average tumor size of $2 \mathrm{HF}$-treated mice. The average wet weight of the tumor at day 60 was also lower in the 2HF-treated groups [2HF (25 mg / kg b.w.): 0.91g, 2HF (50 mg / kg b.w.): $0.57 \mathrm{~g}$. $2 \mathrm{HF}$ (100 mg / kg b.w.): $0.51 \mathrm{~g}$ ] as compared with control mice [2.08g] (Figures 5 and 6B). In addition, the 2HF-treated mice did not exhibit any signs of stress such as impaired movement or posture, indigestion, and areas of redness or swelling. The initial and the final body weights of the control and 2HF-treated mice did not differ significantly (Figure 6C). These results provide critical in vivo evidence for the growth inhibitory effects of $2 \mathrm{HF}$ in breast cancer.

\section{HF regulates the levels of critical tumor proteins in-vivo}

Tumor tissue lysates from $2 \mathrm{HF}$ treated and control MDA-MB-231 mice xenografts were assessed for proliferative, apoptotic and cell cycle markers by Western blot and histopathology. The Western blot analyses of $2 \mathrm{HF}$ treated tumor tissue lysates, as compared with untreated controls, revealed a decrease in the level of proliferation proteins pAKT, survivin, RLIP76, pERK, pJAK2, STAT3, CDK4 and cyclin $\mathrm{B} 1$ (Figure 6D). The 2HF treated tumor tissues also showed a decrease in anti-apoptotic protein BCL-2 and mesenchymal markers vimentin and fibronectin. The Western blot analyses also revealed that the proapoptotic proteins BAX and BIM, apoptosis marker PARP, and normal differentiation marker E-cadherin were increased in 2HF-treated tumor tissue lysates as compared to untreated controls (Figure 6D). The immunohistochemical (IHC) analyses of $2 \mathrm{HF}$ treated breast tumors showed decreased levels of proliferation markers Ki67 and PCNA, angiogenesis marker CD31, and increased levels of epithelial differentiation marker E-cadherin (Figure 7) [33].

Taken together, our results indicate that $2 \mathrm{HF}$ displays strong anticancer effects in breast cancer. $2 \mathrm{HF}$ is a novel natural small phytochemical that can decrease the levels of RLIP76 in breast cancer cells. The

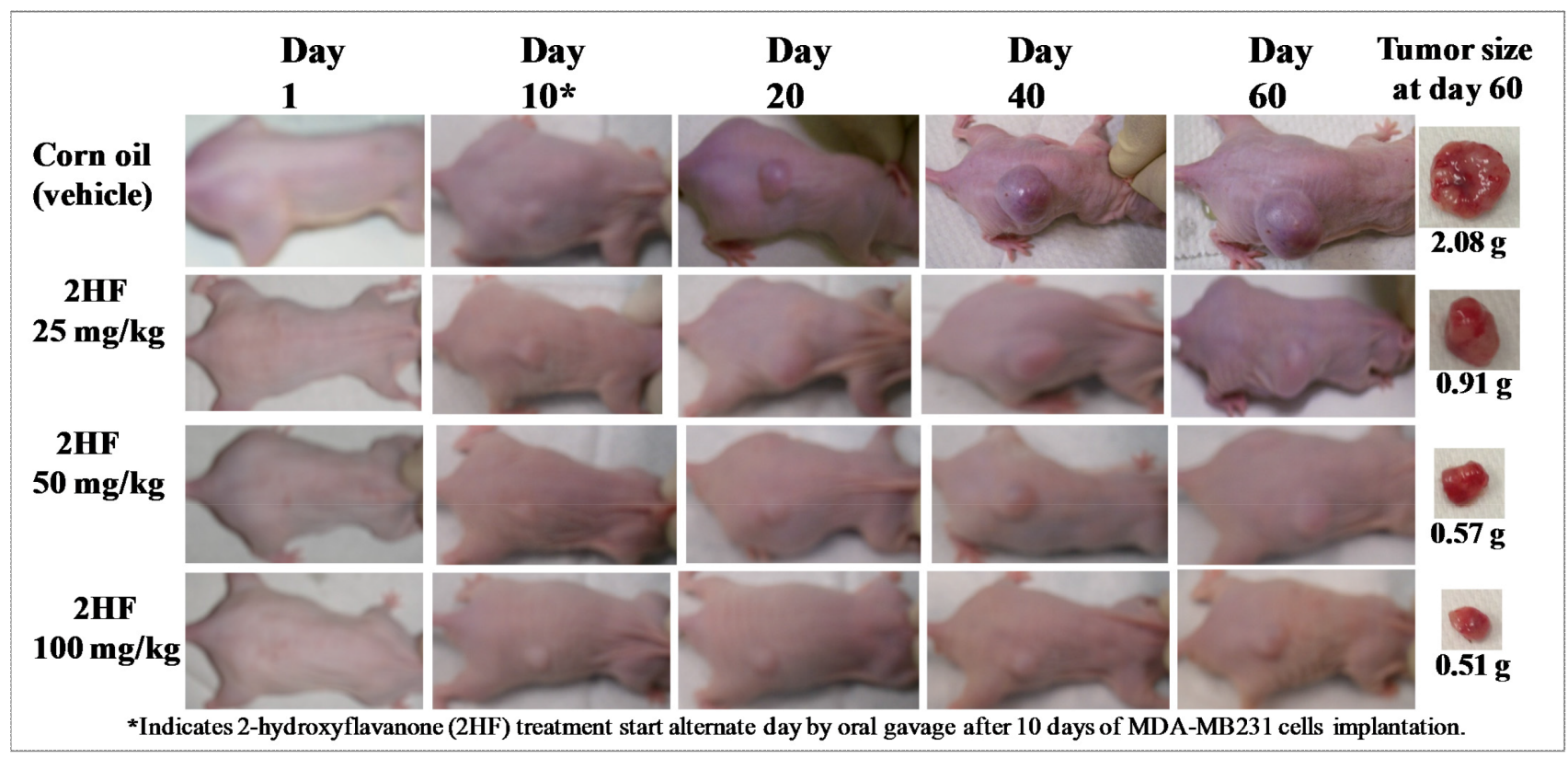

Figure 5: 2HF inhibits progression of triple-negative MDA-MB-231 breast xenograft tumors in nude mice. Hsd: Athymic 8 wk old female nude nu/nu mice were obtained from Charles River, Wilmington, MA, and acclimated for a week prior to start of the experiment. All animal experiments were carried out in accordance with a protocol approved by the Institutional Animal Care and Use Committee (IACUC). Twenty mice were divided into four groups of 5 animals (treated with corn oil (vehicle), and 2HF 25, 50 and 100 mg / kg b.w.). MDA-MB231 cells were suspended in PBS and mixed in a 1:1 ratio with Matrigel. All 20 animals were injected with 1 x $10^{6}$ breast cancer cells (MDA-MB-231) suspensions in $100 \mu \mathrm{l}$ of PBS, subcutaneously into one flank of each nu/nu nude mouse. At the same time, animals were randomized treatment groups as indicated in the figure. Treatment was started 10 days after the MDA-MB-231 cells implantation to see palpable tumor growth. Treatment consisted of 25,50 and $100 \mathrm{mg} / \mathrm{kg}$ b.w. of $2 \mathrm{HF}$ in $200 \mu \mathrm{l}$ corn oil by oral gavage alternate day. Control groups were treated with $200 \mu \mathrm{l}$ corn oil by oral gavage alternate day. Animals were examined daily for signs of tumor growth. Tumors were measured in two dimensions using calipers and body weights were recorded. Photographs of animals were taken at day 1 , day 10, day 20, day 40, and day 60 after subcutaneous injection, are shown for all groups. Photographs of tumors were also taken at day 60. 
efficacy of $2 \mathrm{HF}$ in aggressive, triple-negative MDAMB-231 breast xenograft tumors along with observed effects on critical survival, apoptotic, angiogenic and differentiation proteins further provides both efficacy and mechanistic basis for the anticancer potential of $2 \mathrm{HF}$ in breast cancer.

\section{DISCUSSION}

Effective management of aggressive breast tumors remains a challenge in healthcare. The breast tumors arising from epithelial and basal regions of mammary gland display different characteristics and necessitate different approaches [4]. In addition, the variations in the response to conventional therapies based on hormone receptor status make breast tumors a challenging entity for management [2, 5]. Flavonoids are compounds ubiquitously present in many food sources. These naturally occurring compounds have been linked to multiple biologic functions, such as anti-proliferative, pro-apoptotic, anti-inflammatory, anti-invasive and antiangiogenic effects $[34,35] .2 \mathrm{HF}$ is a novel natural small phytochemical with no overt toxicity towards normal tissues [26]. In the present study, we investigated the molecular mechanisms of $2 \mathrm{HF}$-induced anticancer effects in breast cancer. The treatment of $2 \mathrm{HF}$ led to potent cytotoxic effects as confirmed by multiple cell survival, proliferation and clonogenic assays. $2 \mathrm{HF}$ induced apoptosis and cell cycle inhibition was evident in both $\mathrm{ER}^{+}$ and ER- breast cancer cells.

We also observed that the endogenous protein levels of RLIP76 were increased in breast cancer cells. Hence, we investigated the effect of $2 \mathrm{HF}$ on the levels of RLIP76. 2HF was effective in decreasing RLIP76 protein levels in breast cancer cells irrespective of ER, PR and HER2 status. RLIP76 is a multifunctional protein

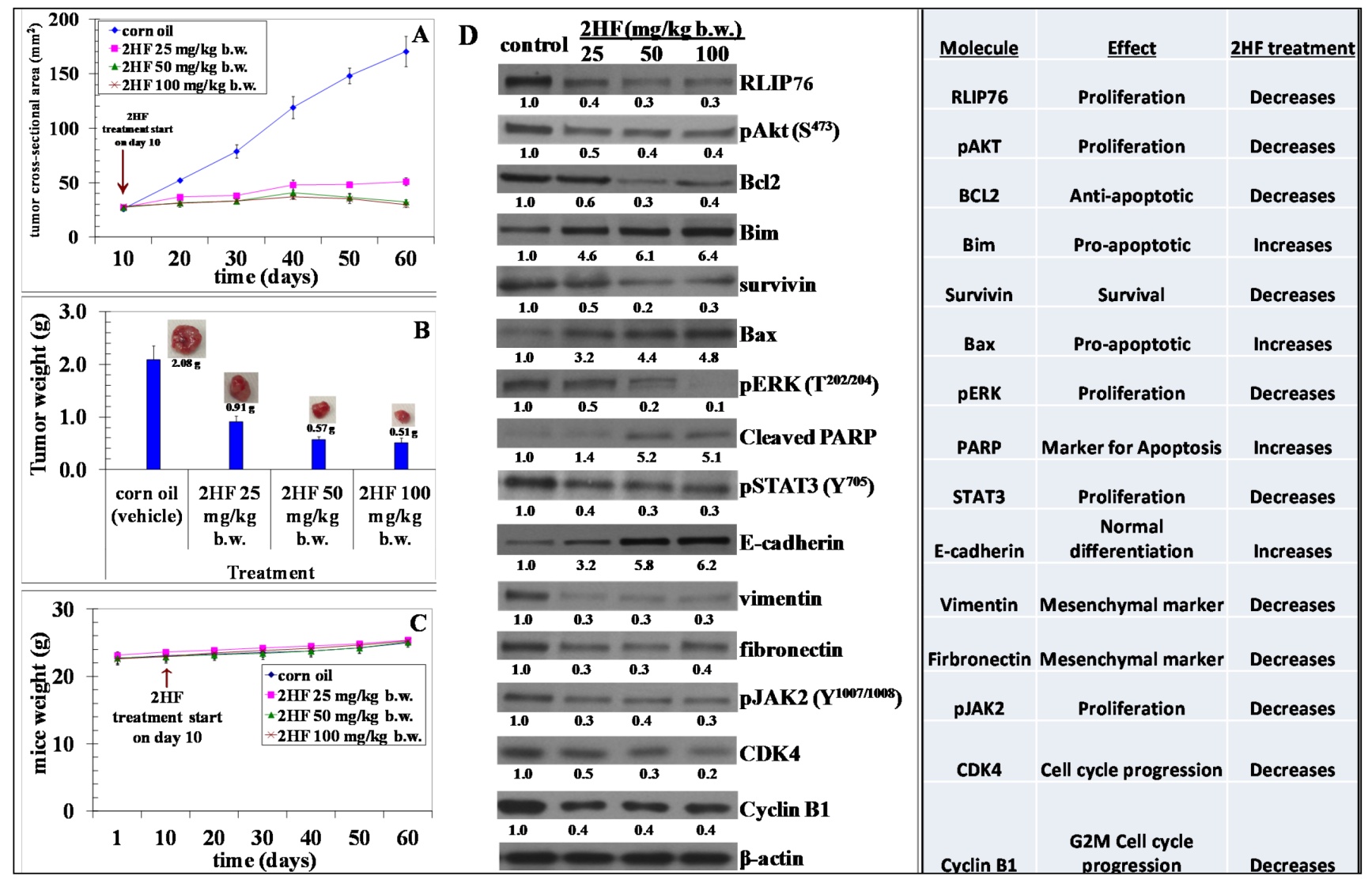

Figure 6: $2 \mathrm{HF}$ decreases final tumor weight and regulates the levels of critical tumor proteins in MDA-MB-231 breast xenograft tumors. Effect of $2 \mathrm{HF}$ on tumor cross sectional area: Tumors were measured by calipers (panel A). Effect of $2 \mathrm{HF}$ on tumor weights: Tumors were excised on day 60 after implantation and weighed before use for immuno-histochemical experiments. The weight of 2HF-treated tumors was found to be statistically different from Controls (corn oil treated) $(p<0.005)$ (panel B). Tumor-bearing mice were weighed over the course of the experiment as a measure of possible $2 \mathrm{HF}$ toxicity (panel C). Effect on cancer signaling pathways in excised tumors from breast cancer xenograft after treatment with 2HF: Western blot analyses of signaling proteins in MDA-MB-231 human breast cancer tumor tissue lysates in Control and $2 \mathrm{HF}$ treated experimental groups. $\beta$-actin was used as a loading control. Numbers below the blots represent the fold change in the levels of proteins as compared to Control as determined by densitometry (panels D). 
which primarily serves as the transporter of glutathioneconjugates (GS-E) of products of lipid peroxidation and chemotherapy drugs, thereby reducing the effective intracellular concentrations of toxic products in cancer cells [36-38]. RLIP76 serves as a rate-limiting step for ligand-receptor endocytosis in cell membrane and regulates the downstream tyrosine kinase signaling that impacts proliferation, survival and apoptosis [14, 15]. The inhibition and/or depletion of RLIP76 is known to exert potent anti-proliferative effects in cancers of lung, colon, prostate, kidney, neuroblastoma and melanoma [16-18, 20, 21].The in vitro results when taken together with the ability of $2 \mathrm{HF}$ to inhibit the tumor progression and decrease RLIP76 protein levels in vivo triple-negative

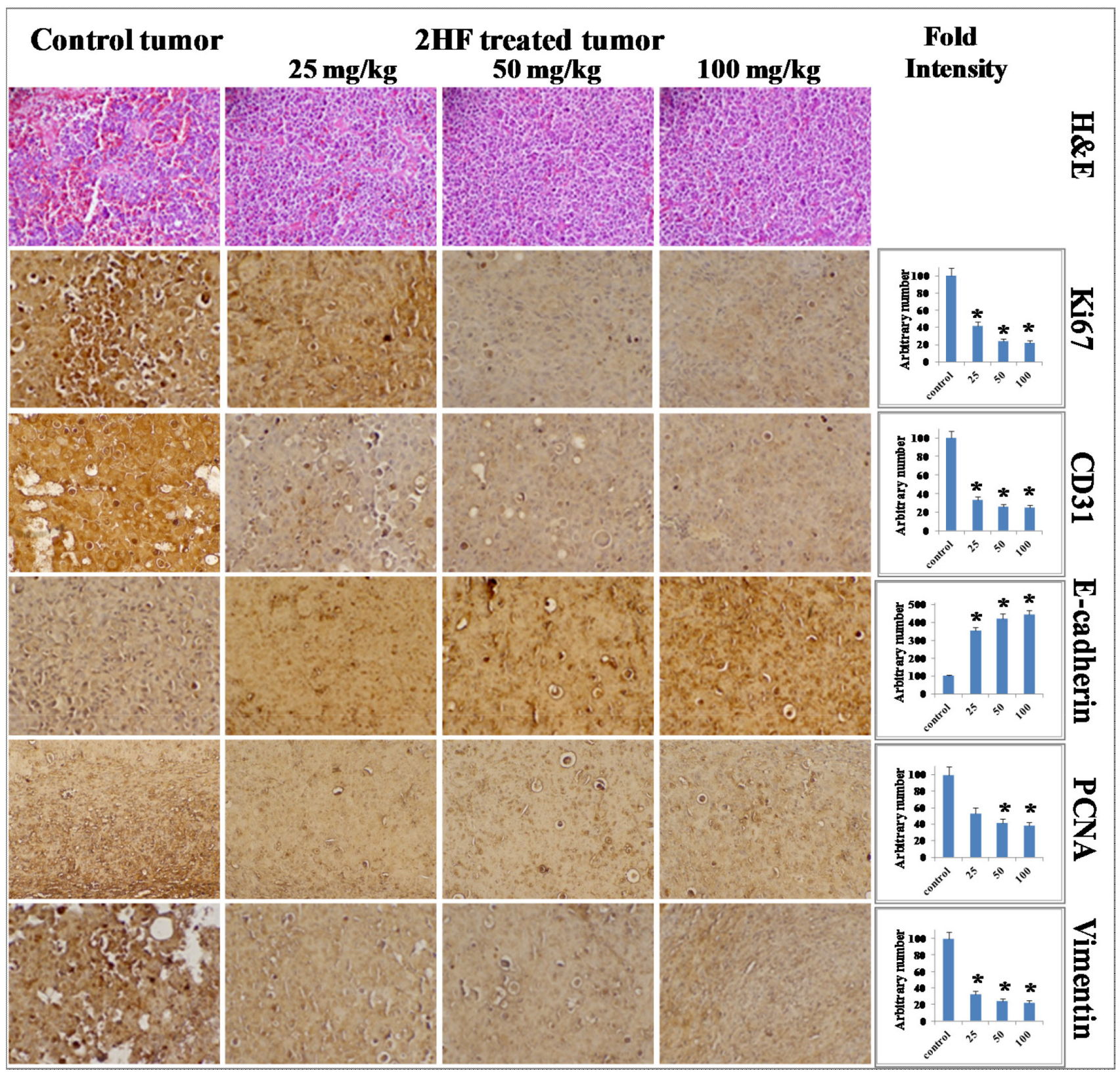

Figure 7: Immunohistochemical analyses revealing that $2 \mathrm{HF}$ inhibits proliferation and angiogenesis markers in MDA-MB-231 breast xenograft tumors. Control and 2HF-treated breast cancer bearing nude mice tumor sections were used for histopathologic analyses. Presented are H \& E stained sections, IHC analyses for the expression of Ki67, CD31, E-cadherin, PCNA, and vimentin. Statistical significance of difference was determined by two-tailed Student's $t$ test. $p<0.001,2 \mathrm{HF}$-treated compared with Control. Photomicrographs at 40x magnification were acquired using Olympus DP 72 microscope. Percent staining was determined by measuring positive immuno-reactivity per unit area. The intensity of antigen staining was quantified by digital image analysis using Pro Plus software. Bars represent mean \pm S.E. $(n=5)$. 
MDA-MB-231 breast cancer xenografts further provides evidence for the role of RLIP76 in mediating the effects of $2 \mathrm{HF}$ in breast cancer.

It is possible that $2 \mathrm{HF}$ could be effective in breast cancer by multiple mechanisms. Several findings in this study are mechanistically novel and translationally significant for targeting aggressive breast cancers. First, the down-regulation of RLIP76 and VEGF consequent to $2 \mathrm{HF}$ treatment is a major and significant finding for both prevention and for targeting aggressive types of breast cancer. RLIP76, along with being a critical regulator of cellular tyrosine kinase signaling cascades, is essential for angiogenesis in tumors [14, 15, 39]. Angiogenesis is especially critical for growth and progression of solid tumors since growth in tumor mass beyond 2-3 $\mathrm{mm}$ is often preceded by an increase in formation of new blood vessels presumably essential for delivery of nutrients and oxygen to the tumor microenvironment $[40,41]$. We initially found that in vitro exposure of breast cancer cells to $2 \mathrm{HF}$ results in the suppression of VEGF levels (Figure 3B). In addition, the present study indicates that the 2HF-mediated suppression of MDA-MB-231 xenograft growth is accompanied by inhibition of neovascularization in the tumor as evidenced by a marked reduction in the vessel area and decrease in CD31, a marker of angiogenesis. This may imply a potential for combination treatments with $2 \mathrm{HF}$ and biologic/or chemotherapeutic agents. Second, we observed a reversal of the pro-/anti-apoptotic ratio of BAX/BCL-2 [42]. Our experiments demonstrate a $2 \mathrm{HF}$-induced down-regulation of anti-apoptotic BCL2 which is paralleled by an increase in pro-apoptotic BAX thereby producing an apoptotic response in MDAMB-231 xenografts. The pJAK2 and its downstream target STAT3, which regulates BCL-2 and survivin levels, were also decreased following $2 \mathrm{HF}$ treatment [43]. Third, reduction of cyclin B1 and CDK4 further confirmed the observed effects of $2 \mathrm{HF}$ on cell cycle. Fourth, epithelial-to-mesenchymal transformation (EMT) leads to increased capacity for survival, invasion and metastatic colonization of tumor cells. In our immunohistochemical analyses, the tumor levels of pro-differentiation marker E-cadherin was increased by $2 \mathrm{HF}$ exposure, which was paralleled by a decrease in EMT markers vimentin and fibronectin. These findings signalize a reversal of immuno-phenotypic changes, paradigmatic for the EMT that can otherwise trigger aggressive tumor growth [44].

Further studies are needed to explore the bioavailability of $2 \mathrm{HF}$ on acute and chronic administration to derive evidence on the dosing of $2 \mathrm{HF}$ for breast cancer prevention and therapy. In conclusion, the ability of 2HF to decrease the levels of RLIP76 and VEGF as observed by both in vitro and in vivo studies and the observed impact on the regulation of critical markers of breast cancer growth, angiogenesis, invasion and therapeutic sensitivity together provide a strong basis for further characterization and development of 2HF for targeting breast cancer.

\section{MATERIALS AND METHODS}

\section{Ethics statement}

No human subjects are involved in the present study. All the animal studies were conducted in following City of Hope Animal Care and Ethics Committee approval according to IACUC protocol \# 12024.

\section{Materials}

2HF (purity $\sim 99 \%$ ), Horseradish peroxidase (HRP)-conjugated anti-mouse, and anti-rabbit secondary antibodies, and MTT were purchased from SigmaAldrich, St. Louis, MO, USA. The CD31, Ki67, ER $\alpha$, cyclin B1, CDK4, BCL-2, survivin, BIM, BAX, pAkt $\left(\mathrm{S}^{473}\right)$, pERK $\left(\mathrm{T}^{202 / 204}\right)$, pSTAT3 $\left(\mathrm{Y}^{705}\right)$, cleaved poly-ADP ribose polymerase (PARP), pJAK2 ( $\left.\mathrm{Y}^{1007 / 1008}\right)$, vimentin, fibronectin, and E-cadherin antibodies were purchased from Santa Cruz Biotechnology (Columbus, OH, USA) and Cell Signaling Technologies (Danvers, MA, USA). ELISA kit for VEGF expression was procured from R \& D Systems (Minneapolis, MN, USA). TUNEL fluorescence and CellTiter-Glo were procured from Promega (Madison, WI, USA). Matrigel was purchased from Corning Life Sciences (Tewksbury, MA, USA). Avidin/biotin complex (ABC) detection kit was procured from Vector (Burlingame, CA, USA). The universal Mycoplasma detection kit was procured from ATCC (Manassas, VA, USA).

\section{Cell lines and cultures}

Human breast untransformed (MCF10a) and cancer (MCF-7, T47D and MDA-MB-231) cell lines were purchased from the American Type Culture Collection (ATCC, Manassas, VA, USA). The authentication of cell lines was done by analyzing fifteen different human short tandem repeat (STR) at Genomic Core, Beckman Research Institute of City of Hope, Duarte, CA, to test for interspecies contamination. The cell lines were last tested in March 2017. All cells were cultured at $37^{\circ} \mathrm{C}$ in a humidified atmosphere of $5 \% \mathrm{CO}_{2}$ in the appropriate medium: DMEM/F12 with $15 \mathrm{mM}$ Hepes buffer, 5\% horse serum, $10 \mu \mathrm{g} / \mathrm{ml}$ insulin, $20 \mathrm{ng} / \mathrm{ml} \mathrm{EGF}, 100 \mathrm{ng} / \mathrm{ml}$ cholera toxin, $0.5 \mu \mathrm{g} / \mathrm{ml}$ hydrocortisone (MCF10a), RPMI-1640 (MCF-7, T47D) and DMEM (MDA-MB-231), medium supplemented with $10 \%$ fetal bovine serum (FBS) and $1 \%$ penicillin/streptomycin $(\mathrm{P} / \mathrm{S})$ solution. All the cells were also tested for Mycoplasma once every 3 months. 


\section{Drug sensitivity (MTT) assay}

Cell density measurements were performed using a hemocytometer to count viable cells resistant to staining with trypan blue. Approximately 20,000 cells were plated into each well of 96-well flat-bottomed micro-titer plates. After $12 \mathrm{~h}$ incubation at $37^{\circ} \mathrm{C}$, medium containing $2 \mathrm{HF}$ (ranging 0-100 $\mu \mathrm{M}$ ) were added to the cells. After $48 \mathrm{~h}$ incubation, $20 \mu \mathrm{l}$ of $5 \mathrm{mg} / \mathrm{ml}$ MTT were introduced to each well and incubated for $2 \mathrm{~h}$. The plates were centrifuged and medium was decanted. Cells were subsequently dissolved in $100 \mu \mathrm{l}$ DMSO with gentle shaking for $2 \mathrm{~h}$ at room temperature, followed by measurement of $\mathrm{OD}_{570}$. Eight replicate wells were used at each point in each of three separate measurements [45-47].

\section{CellTiter-Glo luminescent cell viability assay}

Approximately 10,000 cells were plated into each well of 96-well flat-bottomed micro-titer plates. After $12 \mathrm{~h}$ incubation at $37^{\circ} \mathrm{C}$, medium containing $2 \mathrm{HF}$ (ranging $0-100 \mu \mathrm{M}$ ) were added to the cells. After $48 \mathrm{~h}$ incubation at $37^{\circ} \mathrm{C}$, the 96 -well plate out of the incubator and equilibrate the plate at room temperature for $5 \mathrm{~min}$. Discard the culture media, washed with PBS and add $50 \mu \mathrm{l}$ of PBS in each well. Add $50 \mu \mathrm{l}$ of CellTiter-Glo to each well. Mix contents for 2 min on an orbital shaker to induce cell lysis, and allow the plate to incubate at room temperature for $10 \mathrm{~min}$ to stabilize luminescent signal. Transfer the content from each well of the 96-well plate to a new opaque-walled multi-well plate. Prepared control wells containing PBS without cells and CellTiter-Glo to obtain a value for background, and luminescence was recorded. Eight replicate wells were used at each point in each of three separate measurements [47].

\section{Colony formation assay}

Cell survival was evaluated using a standard colonyforming assay. $1 \times 10^{5}$ cells $/ \mathrm{ml}$ were incubated with $2 \mathrm{HF}$ $(50 \mu \mathrm{M})$ for $24 \mathrm{~h}$, and aliquots of 50 or $100 \mu \mathrm{l}$ were added to $60-\mathrm{mm}$ size tissue culture dishes containing $4 \mathrm{ml}$ culture medium. After 10 days, adherent colonies were fixed, stained with $0.5 \%$ methylene blue for $30 \mathrm{~min}$, and colonies were counted using the Innotech Alpha Imager HP [45].

\section{Cell viability by crystal violet staining}

MCF-7 and MDA-MB-231 cells were seeded into 6-well plates at density of 200,000 cells/well and incubated overnight at $37{ }^{\circ} \mathrm{C}$ prior to $2 \mathrm{HF}$ treatment. 2HF stock was prepared in DMSO and diluted in cell culture medium, and added to each well at the indicated concentrations. Cell viability was measured $48 \mathrm{~h}$ later using crystal violet staining $(0.5 \%(\mathrm{w} / \mathrm{v})$ in $20 \%$ methanol). Absorbance was measured using a Tecan microplate reader (Tecan Infinite M200 Pro, Tecan Group
Ltd., Männedorf, Switzerland). Cell viability of 2HFtreated cells was expressed as a percentage of control cells (i.e. cells treated with equivalent concentrations of the DMSO vehicle). The final concentration of DMSO exposed to the cells was $0.1 \%(\mathrm{v} / \mathrm{v})$ for the duration of the experiment. Values are presented as mean \pm SD from three separate experiments [47].

\section{Annexin V assay}

Apoptosis assays of human breast cancer cells based on loss of membrane integrity were carried out using Annexin V-FITC Apoptosis Detection Kit as described by the supplier (BD Biosciences Pharmingen, San Diego, CA, USA), in which the early- and late-death cells were stained with Annexin V-FITC and PI (propidium iodide). Cells were analyzed using a CyAn ADP cytometer (Beckman Coulter Inc) to quantify fluorescence. Apoptotic cells were defined as Annexin V-FITC positive.

\section{Detection of apoptotic bodies by TUNEL assay}

$1 \times 10^{5}$ cells were grown on the cover slips for $\sim 12 \mathrm{~h}$ followed by treatment with $2 \mathrm{HF}(50 \mu \mathrm{M})$ for 24 h. Apoptosis was determined by the labeling of DNA fragments with terminal deoxynucleotidyl-transferase dUTP nick-end labeling (TUNEL) assay using Promega apoptosis detection system according to the protocol described previously. Slides were analyzed under a fluorescence microscope using a standard fluorescein filter set to view the green fluorescence at $520 \mathrm{~nm}$ and red fluorescence of propidium iodide at $>620 \mathrm{~nm}$ [46].

\section{In vitro migration assay}

Cell migration was determined using a scratch assay. $2 \times 10^{4}$ MCF-7 and MDA-MB-231cells were seeded in 6-well plates to reach $100 \%$ confluence within $24 \mathrm{~h}$ and then treated with $10 \mu \mathrm{M}$ mitomycin $\mathrm{C}$ for $2 \mathrm{~h}$ followed by $25 \mu \mathrm{M} 2 \mathrm{HF}$ treatment. Subsequently, a similarly sized scratch was made with a $200 \mu \mathrm{L}$ pipette tip across the center of each well and immediately imaged at baseline and then at $6 \mathrm{~h}, 12 \mathrm{~h}$, and $24 \mathrm{~h}$ using an EVOS FLAuto Microscope and Imaging system, Thermo Fisher Scientific, San Diego, CA. The rate of cell migration was determined by comparing the sizes of scratch area using Image $\mathbf{J}$ software. Statistically different at $p<0.05$ when compared with control.

\section{Flow cytometry analysis of cell cycle regulation}

The effect of $2 \mathrm{HF}$ on cell cycle distribution was determined by FACS analysis. $2 \times 10^{5}$ cells were treated with $2 \mathrm{HF}$ (ranging from $10-100 \mu \mathrm{M}$ ) for $24 \mathrm{~h}$ at $37^{\circ} \mathrm{C}$. After treatment, floating and adherent cells were collected, washed with PBS, and fixed with $70 \%$ ethanol. On the day of flow analysis, cell suspensions were centrifuged; 
counted and same numbers of cells were resuspended in $500 \mu \mathrm{l}$ PBS in flow cytometry tubes. Cells were then incubated with $2.5 \mu \mathrm{l}$ of RNase (stock $20 \mathrm{mg} / \mathrm{ml}$ ) at 37 ${ }^{\circ} \mathrm{C}$ for $30 \mathrm{~min}$ after which they were treated with $10 \mu \mathrm{l}$ of propidium iodide (stock $1 \mathrm{mg} / \mathrm{ml}$ ) solution and then incubated at room temperature for $30 \mathrm{~min}$ in the dark. The stained cells were analyzed using the Beckman Coulter Cytomics FC500, Flow Cytometry Analyzer. Results were processed using CXP2.2 analysis software from Beckman Coulter.

\section{Immunoblotting}

Tumor tissues from control and 25, 50 and 100 $\mathrm{mg} / \mathrm{kg}$ b.w. 2HF-treated mice were processed for immunoblotting as described by us previously [26]. Supernatant proteins were resolved by sodium-dodecyl sulfate polyacrylamide gel electrophoresis and transferred onto polyvinylidene fluoride membrane. Change in the level of desired protein was determined by densitometric scanning of the immuno-reactive bands. Equal loading of proteins was confirmed by stripping and re-probing the membranes with $\beta$-actin antibodies.

\section{In-vivo xenograft studies}

Hsd: Athymic 8 wk old female nude nu/nu mice were purchased from Charles River, Wilmington, MA, and acclimated for a week prior to start of the experiment. All animal experiments were carried out in accordance with a protocol approved by the Institutional Animal Care and Use Committee (IACUC). Twenty mice were divided into four groups of 5 animals (treated with vehicle only i.e. corn oil and $2 \mathrm{HF}$ at the doses of $0.0025 \%, 0.005 \%$ and $0.01 \% \mathrm{w} / \mathrm{w})$. Exponentially growing MDA-MB-231 cells were suspended in PBS and mixed in a 1:1 ratio with Matrigel. A 0.1 $\mathrm{mL}$ suspension containing $1 \times 10^{6}$ cells was injected subcutaneously on right flank of each mouse above the hind limb. At the same time, animals were randomized into control and treatment groups. Treatment was started 10 days after the MDA-MB-231 cells implantation to see palpable tumor growth. Treatment consisted of $2 \mathrm{HF}$ at the doses of $0.0025 \%, 0.005 \%$ and $0.01 \%(\mathrm{w} / \mathrm{w})$, equivalent to 25,50 and $100 \mathrm{mg} / \mathrm{kg} \mathrm{b}$. w. respectively, in $200 \mu \mathrm{l}$ corn oil by oral gavage alternate day. Control groups were treated with $200 \mu \mathrm{l}$ of corn oil only. Animals were examined daily for signs of tumor growth. Tumors were measured in two dimensions using calipers and body weights were recorded. Each mouse in every group was monitored on alternate days for signs of distress and areas of swelling or redness. Photographs of animals were taken at day 1 , day 10 , day 20 , day 40 , and day 60 after subcutaneous injection, are shown for all groups. Photographs of tumors were also taken at day 60.

\section{Histopathological examination of tumors for angiogenic, proliferative and differentiation markers}

Breast tumors (control as well as 25, 50 and $100 \mathrm{mg}$ / $\mathrm{kg}$ b.w. $2 \mathrm{HF}$ treated) were harvested from mice bearing tumors for $60 \mathrm{~d}$. Tumor samples fixed in buffered formalin for $12 \mathrm{~h}$ were processed conventionally for paraffinembedded tumor sections ( $5 \mu \mathrm{m}$ thick). Hematoxylin and Eosin (H\&E) staining to assess hyperplasia was performed on paraffin-embedded tumor sections. Histopathologic analyses for protein markers with anti-E cadherin to analyze tumor suppressor/ differentiation effects, antiCD31 to visualize blood vessels, anti-Ki67 to assess cell proliferation, anti-vimentin to analyze mesenchymal cells, and anti-PCNA to assess proliferating cell nuclear antigen were also performed, using Universal ABC detection kit (Vector). Statistical significance of difference was determined by two-tailed Student's $t$ test. Immunoreactivity is evident as a dark brown stain, whereas non-reactive areas display only the background color. Sections were counterstained with Hematoxylin (blue). Photomicrographs at 40x magnification were acquired using Olympus DP 72 microscope. Percent staining was determined by measuring positive immuno-reactivity per unit area. The intensity of antigen staining was quantified by digital image analysis using DP2-BSW software. Bars represent mean \pm S.E. $(\mathrm{n}=5) ;{ }^{*} p<0.001$ compared with control.

\section{Statistical analysis}

Each experiment was repeated at least twice to ensure reproducibility of the results. All data were evaluated with a two-tailed unpaired Student's t test are expressed as the mean $\pm \mathrm{SD}$. Changes in tumor size and body weight during the course of the experiments were visualized by scatter plot. The statistical significance of differences between control and treatment groups was determined by ANOVA followed by multiple comparison tests. Differences were considered statistically significant when the $p$ value was less than 0.05 .

\section{Abbreviations}

AKT, protein kinase B (PKB), also known as AKT; BAX, BCL-2-associated X protein; BCL-2, B-cell CLL/ lymphoma 2; BIM, also known as BCL2L11; CD 31, cluster of differentiation 31; CDKs, cyclin-dependent kinases; ER, estrogen receptor; ERBB2, Erb-B2 receptor tyrosine kinase 2 or HER2; ERK, extracellular signal-regulated kinase; PR, progesterone receptor, HER2, human epidermal growth factor receptor 2; 2HF, 2'-hydroxyflavanone; JAK2, Janus kinase 2; Rb, retinoblastoma; RLIP76: A $76 \mathrm{kDa}$ ral-binding protein, RALBP1 or RLIP76; PCNA: proliferating cell nuclear 
antigen; PARP: poly ADP ribose polymerase; STAT3, signal transducer and activator of transcription 3; TUNEL, terminal deoxynucleotidyl transferase-mediated dUTP nick-end labeling; VEGF, vascular endothelial growth factor.

\section{Author contributions}

Conception and design: SSS, DH, LN.

Development of methodology: SSS, JS, LN.

Acquisition of data: SSS, JS, SC, LN.

Analysis and interpretation of data: SSS, JS, SC, LN. Writing, review, and/or edit of the manuscript: SSS, LN, SA, DH.

Study supervision: SSS.

\section{ACKNOWLEDGMENTS}

This work was supported in part by the Department of Defense grant (W81XWH-16-1-0641) and funds from the Perricone Family Foundation, Los Angeles, CA. Funding from the Beckman Research Institute of City of Hope is also acknowledged. The authors are grateful to Dr. Brian Armstrong (Microscope Core Lab, $\mathrm{COH}$ ) and Lucy Brown (Analytical Cytometry Core, $\mathrm{COH}$ ) for the technical assistance in the fluorescence microscope and flow cytometry analyses, respectively.

\section{CONFLICTS OF INTEREST}

The authors declare that they have no conflicts of interest with the contents of this article.

\section{REFERENCES}

1. Jemal A, Siegel R, Xu J, Ward E. Cancer statistics. CA Cancer J Clin. 2010; 60: 277-300.

2. DeSantis C, Jemal A, Ward E, Thun MJ. Temporal trends in breast cancer mortality by state and race. Cancer Causes Control. 2008; 19: 537-545.

3. van de Ven SM, Elias SG, van den Bosch MA, Luijten P, Mali WP. Optical imaging of the breast. Cancer Imaging. 2008; 8: 206-215.

4. Munoz M, Estévez LG, Alvarez I, Fernández Y, Margelí M, Tusquets I. Evaluation of international treatment guidelines and prognostic tests for the treatment of early breast cancer. Cancer Treat Rev. 2008; 34: 701-709.

5. Howlader N, Noone AM, Krapcho M, Miller D, Bishop K, Altekruse SF, Kosary CL, Yu M, Ruhl J, Tatalovich Z, Mariotto A, Lewis DR, Chen HS, et al. SEER Cancer Statistics Review, 1975-2015, National Cancer Institute. Bethesda, MD, http://seer.cancer.gov/csr/1975_2015/, based on November 2016 SEER data submission, posted to the SEER web site, April 2017.
6. Kelsey JL, Gammon MD, John EM. Reproductive factors and breast cancer. Epidemiol Rev. 1993; 15: 36-47.

7. Hulka BS, Stark AT. Breast cancer: cause and prevention. Lancet. 1995; 346: 883-887.

8. Kelsey JL, Bernstein L. Epidemiology and prevention of breast cancer. Annu Rev Public Health. 1996; 17: 47-67.

9. Fisher B, Costantino JP, Wickerham L, Redmond CK, Kavanah M, Cronin WM. Tamoxifen for prevention of breast cancer: report of the National Surgical Adjuvant Breast and Bowel Project P-1 Study. J Natl Cancer Inst. 1998; 90: 1371-1388.

10. Cuzick J, Forbes J, Edwards R, Baum M, Cawthorn S, Coates A. First results from the International Breast Cancer Intervention Study (IBIS-I): a randomized prevention trial. Lancet. 2002; 360: 817-824.

11. Brenton JD, Carey LA, Ahmed AA, Caldas C. Molecular classification and molecular forecasting of breast cancer: ready for clinical application. J Clin Oncol. 2005; 23: 7350-7360.

12. Dawson SJ, Provenzano E, Caldas C. Triple negative breast cancers: clinical and prognostic implications. Eur J Cancer. 2009; 45: 27-40.

13. Lin NU. Breast cancer brain metastases: new directions in systemic therapy. Ecancermedicalscience. 2013; 7: 307.

14. Awasthi S, Singhal SS, Sharma R, Zimniak P, Awasthi YC. Transport of glutathione conjugates and chemotherapeutic drugs by RLIP76 (RALBP1): a novel link between G-protein and tyrosine kinase signaling and drug resistance. Int J Cancer. 2003; 106: 635-646.

15. Singhal SS, Wickramarachchi D, Yadav S, Singhal J, Leake K, Vatsyayan R, Lelsani P, Chaudhary P, Suzuki S, Yang S, Awasthi YC, Awasthi S. Glutathione-conjugate transport by RLIP76 is required for clathrin-dependent endocytosis and chemical carcinogenesis. Mol Cancer Therap. 2011; 10: 16-28.

16. Singhal SS, Roth C, Leake K, Singhal J, Yadav S, Awasthi S. Regression of prostate cancer xenografts by RLIP76 depletion. Biochem Pharmacol. 2009; 77: 1074-1083.

17. Singhal SS, Singhal J, Yadav S, Sahu M, Awasthi YC, Awasthi S. RLIP76 a target for kidney cancer therapy. Cancer Res. 2009; 69: 4244-4251.

18. Singhal J, Yadav S, Nagaprashantha L, Vatsyayan R, Singhal SS, Awasthi S. Targeting p53 null neuroblastomas through RLIP76. Cancer Prev Res. 2011; 4: 879-889.

19. Wu Z, Owens C, Chandra N, Papovic K, Conaway M, Theodorescu D. RalBP1 is necessary for metastasis of human cancer cell lines. Neoplasia. 2012; 12: 969-979.

20. Singhal SS, Awasthi YC, Awasthi S. Regression of melanoma in a murine model by RLIP76 depletion. Cancer Res. 2006; 66: 2354-2360.

21. Singhal SS, Singhal J, Yadav S, Dwivedi S, Boor P, Awasthi YC, Awasthi S. Regression of lung and colon cancer xenografts by depleting or inhibiting RLIP76 (RALBP1). Cancer Res. 2007; 67: 4382-4389. 
22. Awasthi S, Singhal SS, Awasthi YC, Martin B, Woo JH, Cunningham CC, Frankel AE. RLIP76 and cancer. Clin Cancer Res. 2008; 14: 4372-4377.

23. Newman DJ, Cragg GM, Snader KM. Natural products as sources of new drugs over the period1981-2002. J Nat Prod. 2003; 66: 1022-1037.

24. Woodman OL, Chan ECh. Vascular and anti-oxidant actions of flavonols and flavones. Clin Exp Pharmacol. Physiol. 2004; 3: 786-790.

25. Benavente-Garcia O, Castillo J. Update on uses and properties of citrus flavonoids: new findings in anticancer, cardiovascular, and anti-inflammatory activity. J Agric Food Chem. 2008; 56: 6185-6205.

26. Nagaprashantha LD, Vatsyayan R, Singhal J, Lelsani P, Prokai L, Awasthi S, Singhal SS. 2'-hydroxyflavanone inhibits proliferation, tumor vascularization and promotes normal differentiation in $V H L$-mutant renal cell carcinoma. Carcinogenesis. 2011; 32: 568-575.

27. Guthrie N, Carroll KK. Inhibition of mammary cancer by citrus flavonoids. Adv Exp Med Biol. 1998; 439: 227-236.

28. Song JK, Bae JM. Citrus fruit intake and breast cancer risk: a quantitative systematic review. J Breast Cancer. 2013; 16: 72-76.

29. Chavez KJ, Garimella SV, Lipkowitz S. Triple negative breast cancer cell lines: one tool in the search for better treatment of triple negative breast cancer. Breast Dis. 2010; 32: $35-48$

30. Tim M. Rapid colorimetric assay for cellular growth and survival: application to proliferation and cytotoxicity assay. J Immunol Methods. 1983; 65: 55-63.

31. Crouch SPM, Kozlowski R, Slater KJ, Fletcher J. The use of ATP bioluminescence as a measure of cell proliferation and cytotoxicity. J Immunol Methods. 1993; 160: 81-88.

32. Ferrara N, Gerber HP. The role of vascular endothelial growth factor in angiogenesis. Acta Haematol. 2001; 106: 148-156.

33. Zaha DC. Significance of immunohistochemistry in breast cancer. World J Clin Oncol. 2014; 3: 382-392.

34. Hui C, Qi X, Qianyong Z, Xiaoli P, Jundong Z, Mantian M. Flavonoids, flavonoid subclasses and breast cancer risk: a meta-analysis of epidemiologic studies. PLoS One. 2013; 8: e54318.

35. Bode A, Dong Z. Signal transduction and molecular targets of selected flavonoids. Antioxid Redox Signal. 2013; 19: 163-180.

36. Singhal SS, Yadav S, Singhal J, Drake K, Awasthi YC, Awasthi, S. The role of PKC $\alpha$ and RLIP76 in transport-mediated doxorubicin-resistance in lung cancer. FEBS Lett. 2005; 579: 4635-4641.

37. Singhal SS, Yadav S, Singhal J, Awasthi YC, Awasthi S. Mitogenic and drug-resistance mediating effects of $\mathrm{PKC} \alpha$ require RLIP. Biochem Biophys Res Commun. 2006; 348: $722-727$.

38. Awasthi S, Cheng J, Singhal SS, Saini MK, Pandya U, Pikula S, Pikula J, Singh SV, Zimniak P, Awasthi YC. Novel function of human RLIP76: ATP-dependent transport of glutathione-conjugates and doxorubicin. Biochemistry. 2000; 39: 9327-9334.

39. Lee S, Wurtzel JGT, Singhal SS, Awasthi S, Goldfinger LE. RALBP1/RLIP76 depletion in mice suppresses tumor growth by inhibiting tumor neovascularization. Cancer Res. 2012; 72: 5165-5173.

40. Viale G, Slaets L, de Snoo FA, Bogaerts J, Russo L, van't Veer L. Discordant assessment of tumor biomarkers by histopathological and molecular assays in the EORTC randomized controlled 10041/BIG 03-04 MINDACT trial breast cancer. Breast Cancer Res Treat. 2016; 155: 463-469.

41. Yancopoulos GD, Davis S, Gale NW, Rudge JS, Wiegand SJ, Holash J. Vascular-specific growth factors and blood vessel formation. Nature. 2000; 407: 242-248.

42. Cory S, Huang CSD, Adams MJ. The Bcl2 family: roles in cell survival and oncogenesis. Oncogene. 2003; 22: 8590-8607.

43. Wang $\mathrm{X}$, Qiu W, Zhang G, Xu S, Gao Q, Yang Z. MicroRNA-204 targets JAK2 in breast cancer and induces cell apoptosis through the STAT3/BCl-2/survivin pathway. Int J Clin Exp Pathol. 2015; 8: 5017-5025.

44. Kalluri R, Weinberg RA. The basics of epithelialmesenchymal transition. J Clin Invest. 2009; 119: 1420-1428.

45. Singhal J, Singhal SS, Yadav S, Suzuki S, Warnke MM, Yacoub A, Awasthi YC, Awasthi S. RLIP76 in defense of radiation poisoning. Int J Radiat Oncol Biol Phys. 2008; 72: 553-561.

46. Singhal SS, Yadav S, Drake K, Singhal J, Awasthi S. Hsf-1 and POB1 induce drug sensitivity and apoptosis by inhibiting Ralbp1. J Biol Chem. 2008; 283: 19714-19729.

47. Figarola J, Singhal J, Tompkins J, Rogers G, Warden C, Horne D, Riggs AD, Singhal SS. SR4 uncouples mitochondrial oxidative-phosphorylation, modulates AMPK-mTOR signaling, and inhibits proliferation of HepG2 hepatocarcinoma cells. J Biol Chem. 2015; 290: 30321-30341. 